\title{
Stability under Destabilization The Current State of the Chinese Communist Party
}

\author{
Masabaru Hishida (Japan)
}

W hile the phrase "the rise of China's international presence" is a common one today that we ourselves have used countless times since China embarked on its reforms and open-door policies, it has never before been felt truly as much as it is now. This is because behind the argument over the Trans-Pacific Partnership (TPP) as well, which has divided public opinion in Japan to the extent that it brings to mind the closing days of the Tokugawa regime and the debate between opening the country to the outside world or closing it off, is the overwhelming increase in China's presence. To say nothing of international presence, the fact that the core of global economic growth is making a circuit around the globe, crossing the Atlantic and the Pacific to return to China embodies an impact that should be called historical in terms of the history of humankind, above and beyond the trumpeting of the end of the Cold War structure at the end of the preceding century.

But will China really overtake the United States to become the world's superpower? A survey by the Pew Research Center on this question found that 15 of the 22 nations surveyed saw China as either having replaced the U.S. or going to replace the U.S. as the world's leading superpower, with this tendency particularly strong in the European states of France (72\%), Spain (67\%), Britain (65\%), and Germany (61\%) (fig. 1). In contrast, it is quite suggestive that among the nations surveyed Japan showed the highest percentage of respondents who said that China would never replace the U.S., at 60 percent. Japan also had the second smallest percentage of respondents indicating a certain epochй, or suspension of judgment, after France. As such, on the issue of neighboring China alone, despite the criticism sometimes heard that the Japanese people refuse to give clear "yes" or "no" answers, their clarity rivals that of the French. This can be understood as an indication that, due to geographical and/or historical proximity, the alternative images of China as either a "growing China" or a "problematic China" are clearer 
than in other countries.

Figure 1. Will China replace U.S. as world's leading superpower?

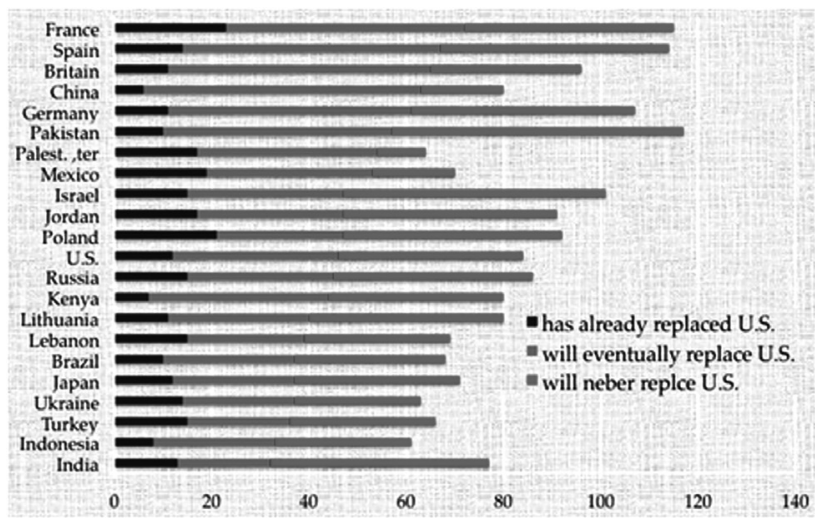

Even a look at the opinions of Americans alone shows that the view that China would become the world's principal leader over the coming 20 years was cited by slightly more respondents than the view that the U.S. would continue to maintain that position, with 38\% giving the former answer and 35\% the latter. In light of the fact that results of a similar survey conducted in 1995 (by Hart-Teeter for WSJ/Nikkei) showed that only $3 \%$ thought China would become the world's principal power while $54 \%$ thought that the U.S. would remain the principal power for the next 20 years, the growth of China, or more precisely Americans' view of China's progress, over the past 15 years is marked. In fact, even in a survey conducted at the end of 2009 the percentage saying that China was likely to become the world's principal leader was higher than that citing the U.S., indicating that American panic that China was closing the gap with the U.S. is not a new phenomenon (fig. 2).

Figure 2. Which nation will be world principal leader?

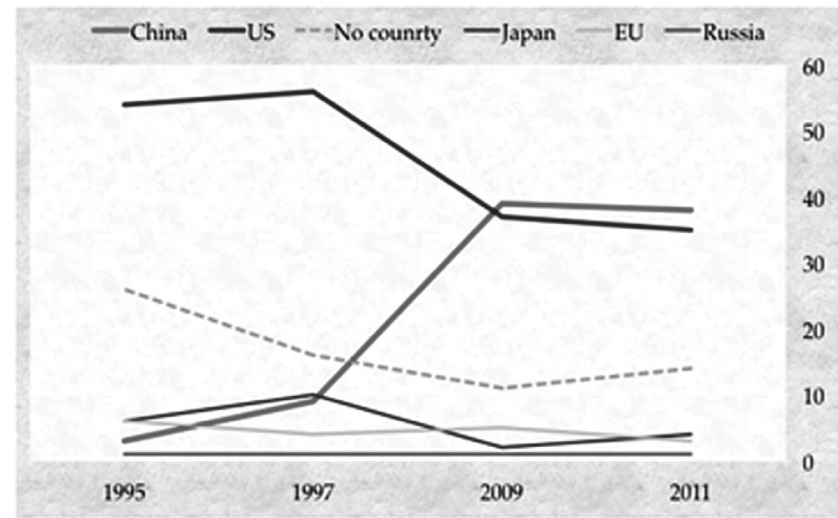


Perhaps because of such panic, while it is true that interest seems to be concentrated especially on the aspects of a "problematic China" such as the spread of corruption in the country, growing disparities or an economic bubble, and concern about its strong foreign policy, it can be argued on further reflection that the faster and more dramatic the growth process the greater and deeper are the resulting contradictions. Here we would like to take a cursory look at today's issues and prospects concerning just how China itself is trying to respond to the diversification and growing complexity of such internal contradictions at the same time its international presence grows, focusing on the aspect of the governance of the Chinese Communist Party, which has marked the 90th anniversary of its formation as a party in 2011.

\section{The success of the "survival strategy"}

But is the continued existence of the Chinese Communist Party as the ruling party for more than 60 years since the People's Republic of China was founded in 1949 on the verge of danger as a crisis phase develops from dramatic external and internal environmental changes brought about by the start of reforms and opendoor policies at the end of the 1970s? Or is the party, the largest political party and the largest interest group in the world, in the process of making its new reason for existence even stronger by recasting the base of its existence, treating such changes as given opportunities? Naming each of these positions the "dusk" and "dawn" position, respectively, and considering both positions from the phases of these transformations in accordance with the analytical factors of organization theory, such as organizational structure, objectives, and membership, what one notices first of all from both is the transformation of the party as an organization, and it is a fact that the internal centripetal force and external support that supported this organization in the past are rapidly wearing away as the ideology of socialism loses effect. A judgment that labels this fact as a crisis is itself the dusk position, or the judgment that as a magnetic force gradually diminishes and/or loses the magnetic field on which it operated an organization that included numerous foreign elements has no path left except that of self-destruction. In contrast, the dawn position sees responses truly suited to the current situation to include improvements such as revisions to the organizational goals and a membership structure inclined toward those with high incomes and high education levels, who should be called the winners of the reforms and openness policies. This view extols breaking away from the ideological restrictions of the past and increasing the ability to respond flexibly to actual circumstances.

It can be said that playing a major role behind this dawn position are the moves of the Chinese Communist Party through now, which the author has named a preventive "survival strategy." Because the party consistently is a proactive actor, 
it definitely has not been caught up in this crisis situation out of ignorance, and neither is it running around in confusion in a panic looking for makeshift measures at this point in time. Rather, the party itself has been the careful, proactive, and determined leader or ruler of this process of transformation since the start of the reforms and openness. Because it is a proactive actor, it has put the lid on the growth of potential opposition forces through co-opting and embracing them. Even actually existing opposition forces are protestors who clearly form a part of the establishment and definitely are not external challengers in opposition to the establishment. The prescience of this organization, which today is calling itself a "learning party," is highly strategic, and at this stage it can be considered successful. Now let's look at a number of political and social phenomena occurring in China's political society in comparison with the outside world, based on this view.

\section{A rash of protests?}

Certainly, demonstrations, strikes, and other social disturbances appear to be unceasing in China. A look at recent developments alone may give the impression that China is in tumultuous chaos, as a brief look at developments over just more than one week before the writing of this paper shows numerous labor disputes and other disturbances, such as protests against the police in Xian, Shaanxi Province spurred by their handling of a fatal traffic accident (December 2, suppressed by hundreds of police officers), a demonstration against delays in payment of wages in Shilingzhen, Huadu District, Guangzhou (December 2, as hundreds of demonstrators blocked roads and thousands of spectators threw stones), a sitin demonstration at Chengdu Qingyang Co. (November 28 - 30, as hundreds of people protested a distribution of assets), a demonstration in Yongzhou, Hunan Province (November 29, with tens of people injured in a conflict with villagers opposing the forced construction of Gaoyan Dam), a demonstration at Hunan Province government offices (November 29, with 400 - 500 Minban school instructors gathering in front of the government offices to demand better pay), a demonstration in Sihui, Zhaoqing, Guangdong Province (November 25, with thousands of people gathering in front of city hall), a demonstration in People's Square, Shanghai (November 23, as about 1000 young intelligentsia rusticated to Xinjiang bore placards with the message “上访无罪、张维敏无罪 ! ”), a strike at a Taiwan-owned electronics factory in Shajingzhen, Bao'an, Shenzhen (November 22, protesting overwork, with hundreds of militia mobilized), a demonstration of villagers in Wukan village, Guangdong Province (November 21 - 22, with about 4000 people demonstrating against improper land deals and voting irregularities, bearing placards with the message “反对官商勾结、还我耕田”), a demonstration at Wuhan city hall (November 20, with about 800 retired military members demonstrating to demand better pay), a demonstration at Jianshe North Road, 
Huadu, Guangzhou (November 18, with hundreds of members of migrant rural labor demonstrating for better pay, bearing placards with the message “还我血 汗銭”、“我要吃饭”), a demonstration by police against a high People's Court in Zhengzhou, Henan Province (November 16, protesting an unreasonable court decision), and a demonstration at a shoe factory in Huangjiangzhen, Dong'wan (November 17, as about 7000 people protested massive pay cuts).

While the scale of participation in these demonstrations of thousands of people brings to mind the image of a rash of severe, major incidents, in consideration of the large denominator of the total population of China and of the powerful interpersonal relations at the base of Chinese society, gatherings of thousands of people at a moment's notice cannot be said to be rare at all. Perhaps to go back to the Japanese sense of things this should be interpreted by removing one digit from each of the crowd figures. In addition, on the whole these were no more than demands for better pay, and as such they differ in phase from large demonstrations or the disturbances that the Chinese authorities cleverly call "expressions of indeterminate dissatisfaction." This is because even if a rash or succession of strikes by workers demanding wage increases or similar demands causes considerable concern on the part of management for avoiding repeat strikes since it is the companies, particularly foreign-affiliated companies, that will suffer the pressure of being forced to institute large wage increases as a result, it does not reach the level of a major direct threat to the structure of governance in China itself.

What China itself fears most and considers very important is a breakdown of public order caused by the growth and spread of disturbances known as sudden large demonstrations. Sudden large group demonstrations have occurred across China since the middle of the first decade of the 21st century, including ones in Wanzhou, Chongqing (2004), Chizhou, Anhui Province (2005), Rui'an, Zhejiang Province (2006), and Dazhou, Sichuan Province (2007). The incident in Wengan, Guizhou Province in June 2008 in particular (along with the incident in Menglian, Yunnan Province, in July) was sufficient in size, with tens of thousands taking part in the demonstration, to shake the authorities.

However, in the eyes of outside observers these sudden large demonstrations are spoken of generally as phenomena of "indeterminate 'protests." That is, since they lack specific subjects of complaint or demands and there are no specific organizations or leaders supporting the whole, it is considered inappropriate to treat these as social movements of protest, and as such they are seen only as simple "incidents." As expressed by the name “泄憤xi efen” given them by Yu Jianrong, the Rural Development Institute at the Chinese Academy of Social Sciences, these are no more than outbreaks of disturbances stemming from cases that have occurred in front of onlookers as literal disorderly crowds, embodying a variety of discontents that have built up, chosen unconsciously as emotional releases, and causing 
demonstrators' actions to get out of control. For this reason, the Weng'an demonstration, for example, was triggered by the direct interest between demonstrators and parties involved in the case of the rape, murder, and disposal of the body of Li Shufen, and there were no factors of solidarity such as a shared consciousness of target value.

It goes without saying that a world with no dissatisfactions at all would be a fantasy Shangri-La and that only an absolutely despotic society could hold down all dissatisfactions completely. Whatever it may have aimed for in the past, it is clear that at this stage contemporary China is neither of the above, and the presence of dissatisfactions can be said to be a universal, normal state of affairs in China. In particular, in light of the dramatic economic growth process, unprecedented in human history, since the start of reforms and openness, inequalities, even in distribution of satisfaction, are unavoidable, and dissatisfaction increases and accumulates more when people's expectations are higher. Among the mass of the people, sufficient breeding ground for advancing true senses of unfairness or dissatisfaction are spreading steadily. These include microeconomic allocations to individuals that are below their expected values despite high macroeconomic growth, the spread of visible disparities in people's own fields of view, and rampant, highly profitable corruption among public officials compared to the small illegalities that individuals conduct. To employ a clumsy metaphor, if a highly flammable material is permeated with combustible material, all that is needed for a quick fire to start is kindling, and explosive combustion can take place with or without ignition. Since the privileged bureaucracy in particular is directly subject to resentment about disparities and corruption, if they address poorly on the spot a situation that has led directly to demonstrations then such large sudden demonstrations can deepen quickly into conflicts between the government and the people. This point is the greatest concern of the Chinese authorities.

\section{A globally synchronized phenomenon?}

When viewed through the lens of this spirit of dissatisfaction with injustices and inequalities such as disparities and corruption, do these demonstrations have the same roots as the spread of protests such as the "Jasmine Revolution" or "Arab Spring" or the Occupy Wall Street movement that shook the world in 2011? Could China be seen as a part of this globally synchronized phenomenon of protest?

First, let's examine this question from the aspect of "xiefen" or release of feelings of dissatisfaction.

One common aspect can be seen between these demonstrations and the Occupy Wall Street (OWS) movement in protest against disparities that started in New York in mid-September and spread to Chicago, Los Angeles, and other locations across the U.S.: the rallying of the $99 \%$ dissatisfied masses against the con- 
centration of wealth among $1 \%$ of the population. Robert Reich has observed that the concentration of income and wealth among the richest people is itself the crux of the difficulties faced by the U.S. economy and that this is an aftershock of the massive economic downturn following the shock occasioned by the collapse of Lehman Brothers. On this point of demonstrating against unfair realities as exemplified by the richest being the sole winners, the undercurrents of OWS and China's protests do overlap. In addition, the facts that these Occupy demonstrations involve a lack of unity in specific objects of protest or specific demands and there is an infinite variety of participants, with no organizations or leaders as mentioned above, and most of all that they lack a major guiding philosophy or ideology permeating throughout the movement can be said to be shared by the large demonstrations in China. Viewed in light of the basic principles of social movement theory, as described above it would be inappropriate to consider these to be movements, but instead they should be judged to be of the level of mere incidents. However, a major point of difference is identified in the presence of such feelings of dissatisfaction themselves. This is related to the fact that behind the concentration of income and wealth in the richest that Reich describes is a sense of loss of the U.S. middle class, which until now has supported the U.S. economy and enjoyed its fruits. As such, one could see the OWS movement as a mass movement led by the young, who see in the collapse of the middle class a premonition of their own future. However, in China the formation of such a middle class has not necessarily advanced, regardless of the proactive efforts by the establishment to develop one as a "buffer" in the existing system. While there are a variety of statistical results depending on how the middle class is defined and confirmed to exist, and the task of such definition itself depends on a variety of objective indicators such as educational background and income or asset level, and doing so itself would involve considerable difficulty, as shown in Table 1 when viewed in terms of self recognition or sense of belonging as an indicator only $7 \%$ of people in China consider themselves to belong to the middle class - incomparable to the level of $45.7 \%$ in the United States. While feelings of dissatisfaction in the U.S. are led by anger in this middle class, in the case of China they can be thought to represent dissatisfaction among the agricultural and laborer classes, which account for overwhelming shares of $45.8 \%$ and $41.5 \%$ of the population, respectively.

Table 1. Class recognition (self image)

\begin{tabular}{|l|c|c|l|c|c|}
\hline \multicolumn{3}{|c|}{ CGSS(2006) } & \multicolumn{3}{c|}{ USGSS (1972-2006) } \\
\hline \multicolumn{1}{|c|}{ class } & respondents & share (\%) & \multicolumn{1}{c|}{ class } & respondents & share (\%) \\
\hline farmer & 4647 & 45.8 & farmer & 2597 & 5.5 \\
\hline worker & 4217 & 41.5 & worker & 21754 & 45.7 \\
\hline middle class & 705 & 7.0 & middle class & 21746 & 45.6 \\
\hline entrpreneur & 85 & 0.8 & entrpreneur & 1545 & 3.2 \\
\hline no answer & 497 & 4.9 & no answer & 1 & 0.0 \\
\hline \multicolumn{1}{|c|}{ total } & 10151 & 100.0 & total & 47643 & 100.0 \\
\hline
\end{tabular}


In addition, in China's case the shadow of the political rhetoric of the Mao Zedong period prior to the period of reforms and opening is a long one, and class consciousness is a special Chinese twist. According to Feng Zhizheng (of the School of Sociology and Population Studies at Renmin University of China), while very high percentages of $91.2 \%$ of those who work as farmers and $94.2 \%$ of those who work as farmers and live in agricultural villages self-identify as being in the agricultural class, only $55.7 \%$ of those who self-identify as being in the agricultural class work as farmers (and only $59.4 \%$ work as farmers and live in agricultural villages) (Table 2). That is, it is a fact of class consciousness in China that about one-half of those who consider themselves to belong to the agricultural class are not farmers. Similar conditions of complication between class categorization based on objective criteria such as household-register categories, residential areas, and job categories and a sense of belonging to a class based on subjective self-identification are seen in the laborer class as well, with about two-thirds of those who self-identify as belonging to the laborer class not being laborers. That is, while $82.0 \%$ of those whose job category is laborer identify themselves as belonging to the laborer class, only $36.4 \%$ of those who selfidentify as belonging to the laborer class work as laborers. This Chinese situation in which one-half of farmers are not farmers and two-thirds of laborers are not laborers means that members of professions such as technocrats and managers who ordinarily should be considered middle class label their own positions as being in the agricultural or working classes, membership in which was once considered an honor politically. Rather than these hypothetical agricultural or laborer classes, the feelings of dissatisfaction in China probably are spreading more among the lower classes. Considering the lower classes to consist of the total of mid-lower and lower levels, the lower classes, which accounted for $50.8 \%$ of the population in 2003 , had grown to $63.3 \%$ in 2006. In particular, the percentage of those in agricultural households identifying themselves as lower class grew rapidly from $45.9 \%$ in 2005 to $69.7 \%$ in the next year, 2006. Perhaps it could be said that the source of Chinese feelings of dissatisfaction is a sense of slipping into the lower classes from hopes of rising to the middle classes. 
Table 2. Twisted Class Consciousness

\begin{tabular}{|c|c|c|c|c|}
\hline \multicolumn{3}{|c|}{ Hukou/Job self-identified class } & "peasant class" & "workes class" \\
\hline \multirow{14}{*}{ Hukou } & \multicolumn{2}{|c|}{ among rural Hukou holders } & 84.8 & \\
\hline & \multirow{6}{*}{ by occupation } & farmer & 91.2 & \\
\hline & & in rural & 94.2 & \\
\hline & & engineer & 67.6 & \\
\hline & & clerk & 62.7 & \\
\hline & & Getihu & 50.0 & \\
\hline & & manager & 71.3 & \\
\hline & \multicolumn{2}{|c|}{ among urban Hukou holders } & & 74.8 \\
\hline & \multirow{6}{*}{ by occupation } & worker & & 56.3 \\
\hline & & in urban & & 82.0 \\
\hline & & engineer & & 68.6 \\
\hline & & clerk & & 80.7 \\
\hline & & Getihu & & 65.0 \\
\hline & & manager & & 61.4 \\
\hline \multirow{6}{*}{ Occupation } & \multicolumn{2}{|c|}{ farmer by occupation } & 55.7 & \\
\hline & & in urban & 21.0 & \\
\hline & & in rural & 59.4 & \\
\hline & \multicolumn{2}{|c|}{ worker by occupation } & & 36.4 \\
\hline & & in urban & & 37.1 \\
\hline & & in rural & & 29.3 \\
\hline
\end{tabular}

The limits of the "power of the Net"

The second point is a difference in the so-called power of the Net. It has been pointed out frequently that the "Net power" of social networking services (SNS) such as Facebook and Twitter is the driving force behind the "Jasmine Revolution." This is proclaimed to be proof that the Internet can be a weapon to overturn heavy-handed politics as the reasonable resistance of young people against unemployment, corruption, and suppression of human rights can cross the boundaries between generations to become intergenerational collaboration and draw in the entire national public.

Behind this is the point of view that says that while the OWS and Jasmine Revolution movements have been ridiculed as "headless" or "boneless" revolutions due to their lack of leaders and organizations, in an environment of information technology that has advanced under globalization the traditional organizational structure and leaders are unnecessary in an understanding of conventional movement concepts, with the spread of the Net society compensating for their absence. This can be said to be making the point that the Jasmine Revolution is a new type of revolution driven by the power of the Net, as the "headless" or "boneless" nature of the movement is more than made up for by dispatch and propagation of information through SNS.

However, the level of this "power of the Net" has been only very limited in the phenomenon of protests in China. Still, it is true that the presence today of 485 million Netizens in China (with Internet penetration of $31.8 \%$, or $12 \%$ in rural areas), as typified by the power of communication of information using Weibo microblogs, should not be underestimated. 
To begin with, in the Maghreb states and other parts of the Middle East and Africa, sites such as Facebook and Twitter are freely accessible, and the most important structural element of the Jasmine Revolution is the high level of efficacy of social media when compared to the mainstream media in terms of communication and dispatch of information. However, in China the building of the information-technology society itself has been conducted under the leadership of the national government from the start.

This itself can be said to represent China's survival strategy anticipating the importance and the danger of the IT revolution. Since 1993, China's government has established the national information-technology strategy called the "The Golden Projects" toward application of information technology in finance and other fields and adoption of e-government. However, part of this strategy is the "The Golden Shield Project" intended to develop information-management systems in the public-security sector. In September 1998 the Ministry of Public Security formulated the Golden Shield Project, and since ratification of the plan in the State Council it has been implemented through activities ranging from blocking harmful sites to implementing a personal-information management system and monitoring of access data, among others. The goal is to develop a comprehensive information monitoring/collection system including aspects such as control of departure and entry, a fingerprint databank, pattern recognition (including voice recognition and visual and facial recognition systems), interception of email and telephone calls, personal identification cards, and a fiber-optic network. In the 16th general meeting of the Central Committee this fall, a decision on development of cultural industries as main industries supported strengthening of social controls including controls on the Internet, a development in accordance with this direction.

Thus, despite the fact that there are a number of apparent commonalities with the Arab Spring in Tunisia, Egypt, Syria, Libya, and elsewhere, China probably can be said to have no relation to its impact. While in the nations of North Africa and the Middle East information on suicide protests by young people was circulated on the Internet as news of major incidents, helping to trigger the Jasmine Revolution, ironically in China such incidents already are old news due to the careful and bold spread of IT and SNS as part of the above preventive survival strategy. The level of Chinese Netizens' immune strength to such shocking incidents cannot be compared to other countries. Truly the frequency of such incidents and the spread of information on them through the Internet as a means of communication of information has only lessened their impact.

In addition, the element of people serving as symbols cannot be ignored. In Chinese politics, rather than dictatorship by an individual as in the nations where the Arab Spring occurred, governance is conducted by the party, or the politi- 
cal system of the state. Where there is no clear subject to overthrow, it is difficult to increase the cohesion of the revolutionary movement. Those on the offensive have no clear person in leadership as seen above, and furthermore the subject of their attacks lacks a clear individual dictator. In addition, in comparison with the case of the Arab states where the revolutions had strong tinges of being driven by desperation or poverty in light of factors such as the spread of poverty and unemployment, particularly the spread of unemployment among the young, in China the equations "despair $<$ dissatisfaction $<$ hope" and "fear $<$ temptation" remain unyieldingly in place, so that a downward trend in cohesive power cannot be denied.

As an additional remark, since there is another difference in the directions of international support from Western nations and others, who fear a collapse of China as a nightmare, to China at this stage in time Jasmine must not be considered a sweet-smelling thing, and it is unlikely that it will come to full blossom.

An overwhelming sense of trust

As a final point, this paper will close by reaffirming two survey results as being in agreement with this judgment. Fig. 3 shows some results of a survey of public opinion in 134 countries around the world, conducted by Pew Research mentioned above, on the subject of satisfaction in the state of one's own country. Satisfaction in China was exceptionally high. While in developed countries satisfaction was in the $20 \%$ range on the whole, it was much higher in China, at 83 percent. What's more, a look at historical trends since 2006 shows that while satisfaction is in a decreasing trend year by year in other countries, in China alone does it show an increasing trend, rising from the $70 \%$ range to the $80 \%$ range. In the case of China, the sense of expectations for the future of the country stands out, confirming that China, with its strong hope for the future embodied in the nation, belongs to a completely different phase than the Jasmine countries.

Figure 3. Satisfaction with Country's Direction

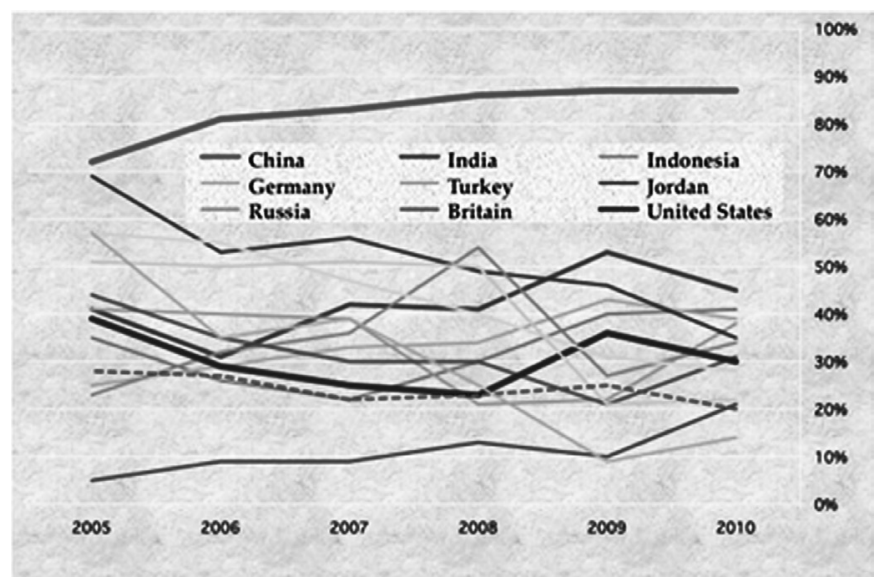


In addition, as expressed by the popular saying in China "Local leaders at the township level are devils, those at the district level are villains, those at the provincial level are family, and the central leaders in Beijing are benefactors," the subjects of dissatisfaction, particularly dissatisfaction with government, are concentrated on local leaders, with the sense of trust increasing at higher levels in the administrative hierarchy, so that more than $90 \%$ of survey subjects reported high levels of trust in the party Central Committee and the State Council.

Figure 4. High levels of trust in the party Central

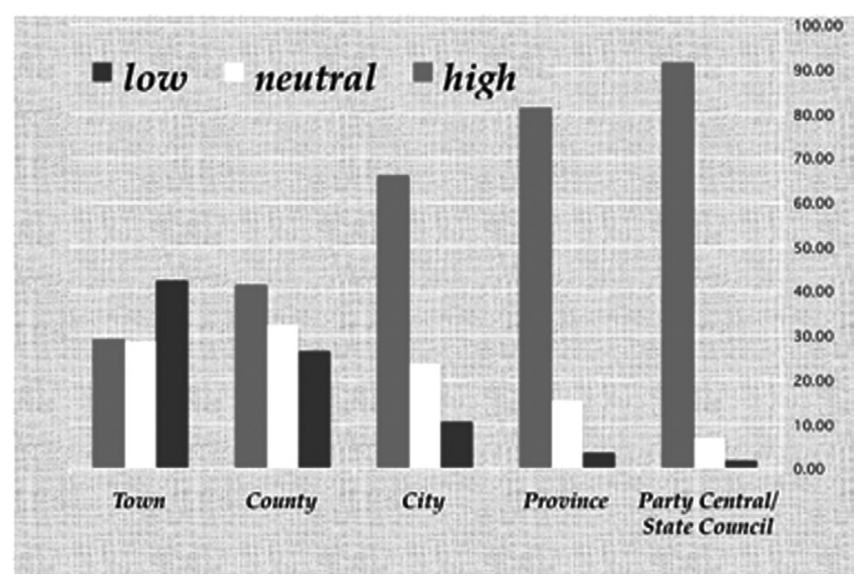

There is no room for disagreement with the fact that China's society is becoming more fluid and unstable. However, from our considerations here we can reject the dusk position that says that China's political and economic system is in danger of falling in the near future into a state of chaos in which the party will no longer be able to exert control. At the present stage, governance by the Chinese Communist Party is enjoying the fruits of the preventive survival strategy, and as such the party is likely to be able to make it to at least its 100th anniversary by maintaining stability under unstable conditions. 